\title{
Study of surgical management of trochanteric fracture of the femur with dynamic hip screw
}

\author{
D Rao R. ${ }^{1}$, PV Chowdary R. ${ }^{2 *}$, Aditya K. ${ }^{3}$, Deedi K. ${ }^{4}$ \\ DOI: https://doi.org/10.17511/ijoso.2020.i02.04 \\ 1 Rama D Rao, Associate Professor, Department of Orthopedics, GSL Medical College, Rajamahendravaram, Andhra Pradesh, India. \\ 2* Ramana PV Chowdary, Assistant Professor, Department of Orthopedics, GSL Medical College, Rajamahendravaram, Andhra Pradesh, \\ India. \\ ${ }^{3}$ Aditya K, Resident, Department of Orthopedics, GSL Medical College, Rajamahendravaram, Andhra Pradesh, India. \\ ${ }^{4}$ Kiran Deedi, Central Research Laboratory, GSL Medical College, Rajamahendravaram, Andhra Pradesh, India.
}

Background: The use of a dynamic hip screw (DHS) for stable trochanteric hip fracture fixation has been successfully applied in fracture healing for more than 20years. DHS fixation on unstable trochanteric fractures still has a more failure rate, particularly in osteoporosis patients. Thus, this study is aimed to investigate the biomechanical property of the DHS system to provide the lesser trochanter fragment stable fixation. Material and methods: This cross-sectional, observational, and follow-up study was conducted in the Department of Orthopedics, GSL Medical College and General Hospital, Rajamahendravaram with a total of 40 cases of trochanteric fractures. All surgeries were performed under spinal anesthesia. Surgery done was an internal fixation with DHS and 135degree angled blade plate. Results: Among 40 cases, $32.5 \%$ were Type I, and $67.5 \%$ were Type II Trochanteric fractures. $40 \%$ cases had grade 3 osteoporosis and $30 \%$ had grade4-osteoporosis rest of the patients were having grade $2(20 \%)$, grade $5(7.5 \%)$, grade $6(2.5 \%)$ and grade $1(0 \%)$, according to Singh's index. The clinical and functional outcomes of the procedure were excellent in 10 hips (25\%), Good in 20 hips (50\%), Fair in 6 hips (15\%), and $4(10 \%)$ of the patients had poor results. Conclusions: Trochanteric fractures are essentially fractured of the elderly, with osteoporotic bones. The dynamic hip screw is the operative treatment of choice for stable trochanteric fractures.

Keywords: Fracture, Hip, Trochanteric, and dynamic hip screw

Corresponding Author

Ramana PV Chowdary, Assistant Professor, Department of Orthopedics, GSL Medical College, Rajamahendravaram, Andhra Pradesh, India. Email: gslcentralresearchlab@gmail.com
How to Cite this Article

To Browse

Rao RD, Chowdary RPV, Aditya K, Deedi K. Study of surgical management of trochanteric fracture of the femur with dynamic hip screw. Surgical Review Int J Surg Trauma Orthoped. 2020;6(2):87-92. Available From https://surgical.medresearch.in/index.php/ijoso/artic le/view/169

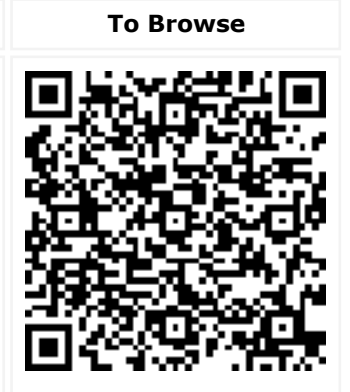




\section{Introduction}

Trochanteric fractures of the femur are common in the old age group, but it is not uncommon in the younger age group. Trochanteric fractures unite readily with the traditional line of treatment. Unlike fractures of the neck of the femur, there is no fear of complications like vascular necrosis of head and its sequelae of osteoarthritis. Though trochanteric fractures unite without surgical intervention, malunion with coxavara deformity resulting in shortening of limb and limp are commonly seen [1]. Until surgical operative treatments involving the use of several implants were introduced in the 1950s, hip fractures were managed during conservative methods based on traction and bed rest [2]. Various operative procedures with different implants have been described for the treatment of trochanteric fractures. Earlier active treatment was usually delayed for as long as three to four weeks because it was believed that attempts to immobilize the limb by splints traction or open reduction by means of internal fixation would be fatal but this usually leads to secondary complications. The primary goal of treatment has to be early mobilization to avoid secondary complications which can be achieved by a dynamic hip screw which is operative treatment of choice for trochanteric fracture as it allows early weight-bearing and lower complication than other implants. Here is an effort to study the results of the dynamic hip screw in the management of trochanteric fracture by analyzing the factors which influence post-operative mobility.

\section{Material and Methods}

Settings: This cross-sectional and observational study of patients with trochanteric fractures of the femur that were treated with DHS was conducted at Department of Orthopedics, GSL Medical College and General Hospital, Rajamahendravaram, Andhra Pradesh, India.

Duration of study: Two years, December 2016 to December 2018

Sampling method: Simple random sampling technique

Inclusion and exclusion criteria: Patients who have above eighteen years of age, both male and females have been diagnosed with having a trochanteric fracture, and patients who are fit for surgery were included. Patients below the age of eighteen years. Patients with sub-trochanteric and
Reverse oblique trochanteric fractures (Unstable fractures). Patients with old un-united trochanteric fractures. Patients who are unfit for surgery, Patients with pathological fractures, patients with uncontrolled diabetes mellitus and chronic renal failure, and patients with pathological fractures were excluded.

Scoring system: Trochanteric fracture was classified as Type I and II according to Boyd and Griffin [3]. Radiological grading of osteoporosis was done using Singh's Index [4].

Data collection: By interview, by follow-up at intervals of $1,2,4,6$ months postoperative and by analyzing case papers.

Surgical procedure: Patients admitted with trochanteric fractures were examined and $\mathrm{x}$-rays of the hip were taken. Skin traction was applied routinely in all cases. All surgeries were performed under spinal anesthesia. Surgery done was an internal fixation with DHS and 1350 angled blade plate. Cephalosporin and were used 24hours preoperatively, intraoperatively and 5 days postoperatively, and oral antibiotics till suture removal. The clinical and functional outcome of the procedure was calculated using Kyle's criteria [5].

Data analysis: All the data were expressed in number and percentage by using MS excel 2013.

\section{Results}

The average age for the whole group was 61.53 years. Most of the patients were in the age group of 51 to 70 years i.e. 22 patients (55\%). The majority of the patients in this study were older individuals. There were females $26(65 \%)$ as compared with males 14 (35\%), thus showing female preponderance. Among 40 cases, $67.5 \%$ were Type II and $32.5 \%$ were Type I according to Boyd and Griffin's Classification of Trochanteric fractures. $40 \%$ cases had grade 3 osteoporosis and $30 \%$ had grade4-osteoporosis rest of the patients were having grade $2(20 \%)$, grade $5(7.5 \%)$, grade $6(2.5 \%)$ and grade1 $(0 \%)$, according to Singh's index. The clinical and functional outcome of the procedure was calculated using Kyle's criteria. The results were excellent in 10 hips (25\%), Good in 20 hips $(50 \%)$, Fair in 6 hips $(15 \%)$, and $4(10 \%)$ of the patients had poor results. Under the postoperative protocol, patients allowed to sit upon the bed on 2nd and 3rd day, Isometric quadriceps >exercises started from 2nd day, Hip and knee flexion exercises from or 7th day, patiently allowed 
Non-weight bearing walking form 10th day, Partial weight-bearing started when radiological signs of the union were present average 6th week postoperative, full weight-bearing after the clinical and radiological union. Patients above the age of 40 years with radiological evidence of osteoporosis were treated with vitamin-D and calcium substitutes and the average stay in hospital was 18 days.

Table1: Clinical characteristics of the study population.

\begin{tabular}{|c|c|c|c|}
\hline Characteristics & $\begin{array}{c}\text { Classifica } \\
\text { tion }\end{array}$ & $\begin{array}{c}\text { Number of Patients } \\
(\mathrm{n}=40)\end{array}$ & $\begin{array}{c}\text { Percentage } \\
(\%)\end{array}$ \\
\hline \multirow[t]{4}{*}{ Age } & $41-50$ & 07 & $17.50 \%$ \\
\hline & $51-60$ & 15 & $37.50 \%$ \\
\hline & $61-70$ & 07 & $17.50 \%$ \\
\hline & $71-80$ & 11 & $27.50 \%$ \\
\hline \multirow[t]{2}{*}{ Gender } & Female & 26 & $65 \%$ \\
\hline & Male & 14 & $35 \%$ \\
\hline \multirow{2}{*}{$\begin{array}{l}\text { Type of fracture (Boyd and } \\
\text { Griffin's) }\end{array}$} & Type I & 13 & $32.50 \%$ \\
\hline & Type II & 27 & $67.50 \%$ \\
\hline \multirow{6}{*}{$\begin{array}{l}\text { Type of fracture (Singh's } \\
\text { index) }\end{array}$} & Grade I & 0 & 0 \\
\hline & Grade II & 08 & $20 \%$ \\
\hline & Grade III & 16 & $40 \%$ \\
\hline & Grade IV & 12 & $30 \%$ \\
\hline & Grade V & 03 & $7.5 \%$ \\
\hline & Grade VI & 01 & $2.5 \%$ \\
\hline \multirow{3}{*}{$\begin{array}{l}\text { Functional outcome } \\
\text { (Kyle's criteria) }\end{array}$} & Excellent & 14 & $35 \%$ \\
\hline & Good & 20 & $50 \%$ \\
\hline & Fair & 06 & $15 \%$ \\
\hline
\end{tabular}

Data were expressed in number $(n)$ and percentage (\%).

Fig-1: Trochanteric fracture Left side -ORIF with DHS Trochanteric fracture of femur: excellent outcome.

Pre-op
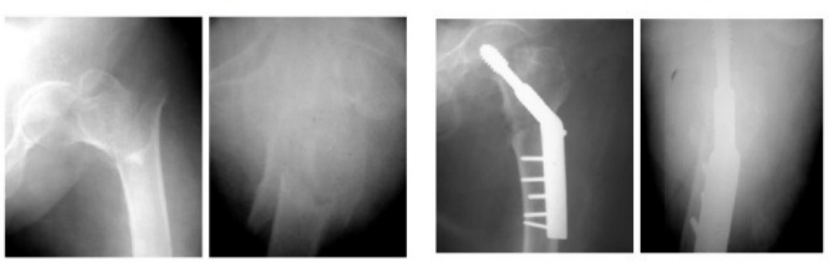

3 Months Post -Op

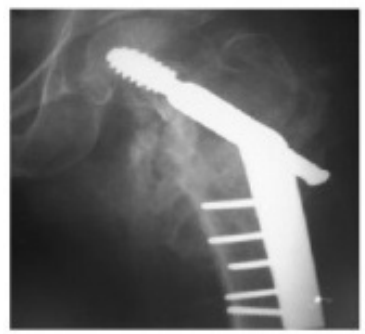

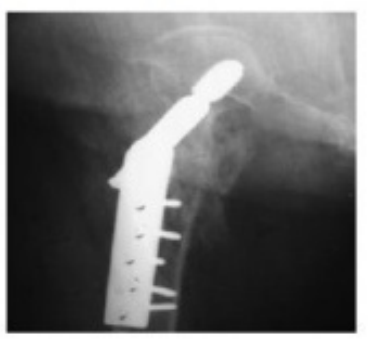

\section{Months Post -Op}
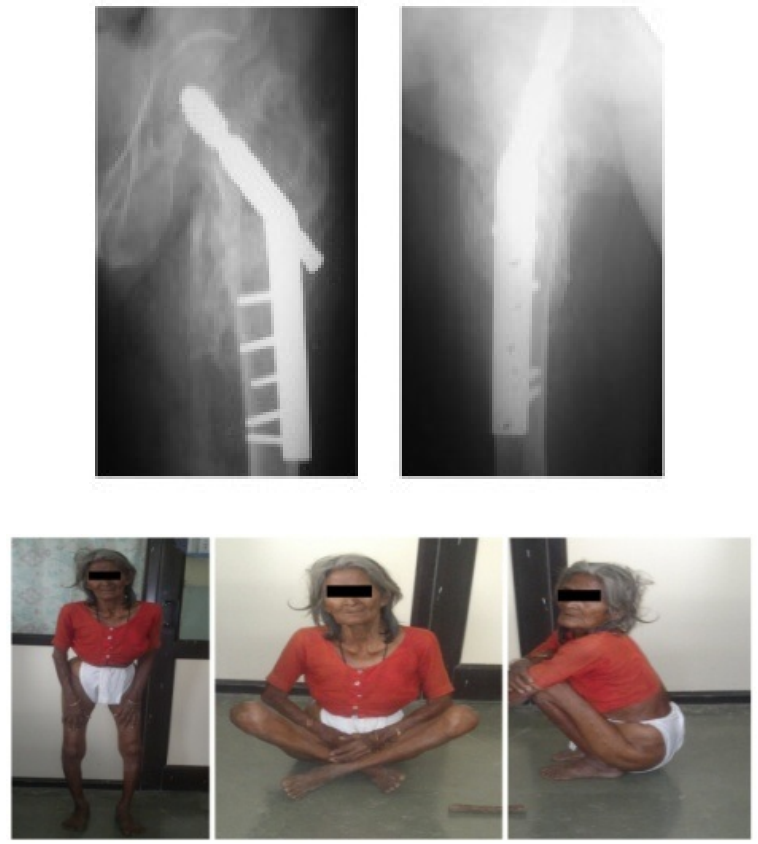

Fig-2: Trochanteric fracture Left side- ORIF with DHS Trochanteric fractures of femur: good outcome.
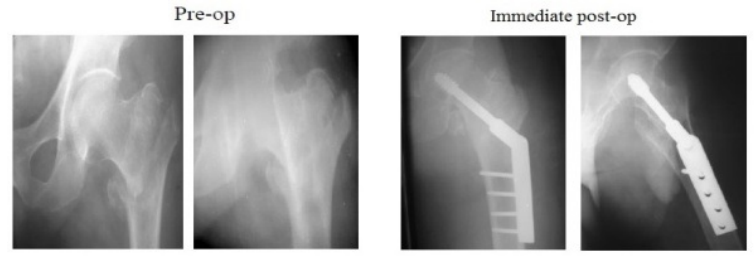

1 month post op
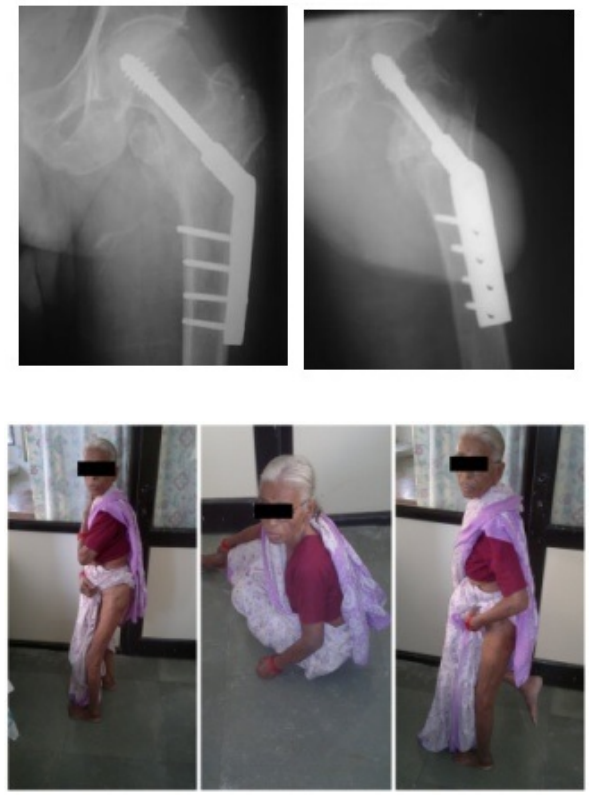

Fig-3: Trochanteric fracture Left side ORIF with DHS Trochanteric fracture of femur: fair outcome. 


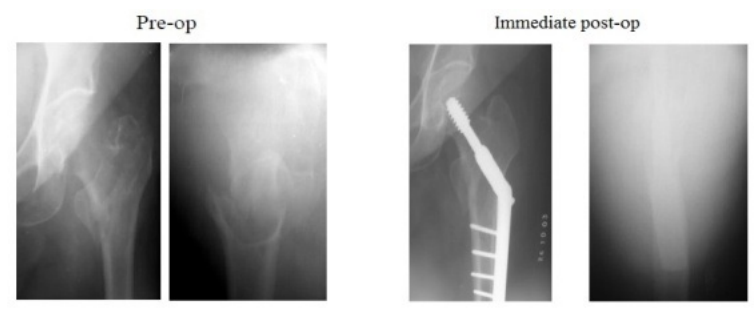

1 Month Post - Op

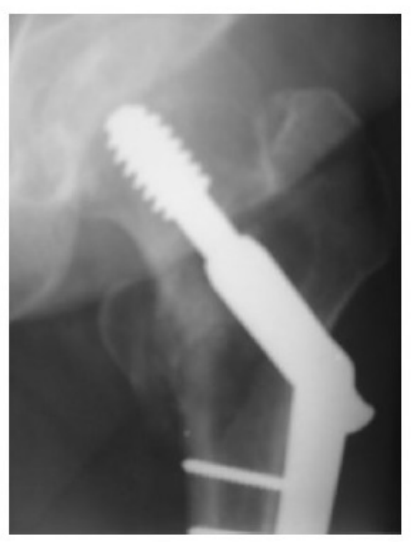

3 Months Post - Op
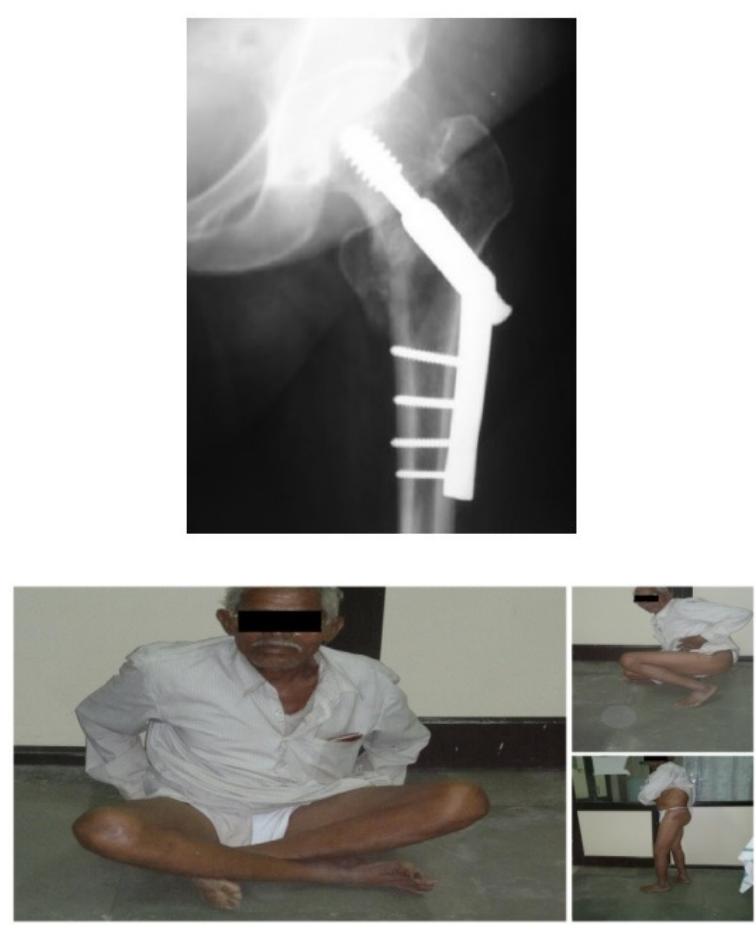

\section{Discussion}

The treatment for intertrochanteric fractures has evolved significantly form the last few decades. Several methods were introduced for fixation for fractures. Among all DHS could be considered as the gold standard for fixation of intertrochanteric fractures. Ecker et al., [6] reported that operative treatment is the procedure of choice for trochanteric fracture if a skilled anesthetist and surgeon, adequate instruments operation theatre conditions
Are available, and more debilitated the patient is, more the need for surgery. The goal of the treatment is to restore the patient to the preoperative status as early as possible with open reduction and stable internal fixation to all early ambulation. Parker et al., [7] stated that qualityadjusted life years and cost of several type hip fracture with various treatment options showed that operative treatment proved cost-effective than conservative treatment for extracapsular fractures. In the present study, the majority of type II fractures were observed and this result was consistent with a prospective study of 20 cases of fresh trochanteric fractures admitted to tertiary care hospital, Surat [8], a study with 20 elderly high-risk subjects with an intertrochanteric fracture. From Orthopedic Department, Al-Menoufia University Hospital, Egypt [9], and also a prospective comparative study from Pondicherry, India [10]. Gurtler [11] reported biomechanical evaluation of fixation of unstable fractures with Enderspins, Harris condylocephlic nails, and compression hip screws. They found that the dynamic hip screw was five times more rigid than condylocephalic nails. Esser et al., [12] found no difference between DHS and Jewett Nail plate regards to the length of hospital stay, mortality, and morbidity, but at the end of six months, more patients treated with DHS were mobile with significant radiological evidence of better compression without loss of fixation. Moore [13] in a comparison of treatment with Richard's DHS and Jewett Nail plate for trochanteric fractures found that reoperation rate with Jewett nailandplatewas13\% compared to $6.5 \%$ with Richard's dynamic hip screw. This was because of more frequent implant penetration into the hip joint and superior cut through with Jewett nail and plate, as this is a rigid implant compared to Richard's screw, which is a dynamic implant. In this study, $50 \%$ of trochanteric fracture of the femur on the right-hand side and left-hand side similar result was also observed in a prospective comparative study with 30 adult individuals from Pondicherry, India [10]. In this study, it was no pathological fractures in the present study which were seen in other series between 20 to $25 \%$ by Waddell et al [14]. In the present study, majority of fractures were noted in females than in males and this result was consistent with a study conducted with 2150 patients of 50 years and older, with a diagnosis of hip fracture, discharged from two local acute care hospitals over a 5 year period [15], In a descriptive study from Turkey [16] but contrast result was observed in a 
Prospective study from tertiary care hospital, Surat [8]. In the present study, the majority of fractures belong to grade III and grade IV and a similar result was observed in a study was done in Yenepoya Medical College, Mangalore [17], a retrospective study Tamilnadu [18]. The average duration of stay for patients treated with DHS was 18.2 days in the present study but from a retrospective cohort study from Korean was only 10 days [19], a retrospective observational from the USA was 15.7 days [20], a prospective study from Victoria and Bowring and Lady Curzon Hospitals, Bangalore was 25 days [21] and the final outcome of fracture healing was good in the majority of cases this result was consistent with the study conducted with 60 patients above 50 years of age with intertrochanteric fractures of Femur admitted in JSS Hospital, Mysore [22]. Parker et al., [23] reported that the screw has to be placed centrally or inferiorly on the anteroposterior view and centrally on the lateral view. In this study also the same principle of placement of screw was followed. The types of hip fractures were different in women and men with age. The pattern difference reflects differences in type and rate of bone loss in genders, but it is conjectured that the changing rate and pattern of falling with increasing age may also be important [15]. Lee et al., 2007 concluded, intertrochanteric fractures treatment was safe, effective, and simple method was minimally invasive with dynamic hip screw / conventional dynamic hip screw. The little invasive technique as different from the conventional technique has lower pain levels, smaller wound size, and lower blood loss. Hospital stay and total analgesic use were also decreased, and this was a benefit to the patient and reducing hospital expenses [24]. The dynamic hip screw is still the gold standard for treating intertrochanteric fractures. Conclusions drawn on evidence-based medicine are; given the lower complication rates, a sliding hip screw is superior for intertrochanteric fracture fixation. More studies are needed to determine whether IM nails are superior to select fracture types (reverse oblique fractures). The sliding hip screw remains the implant of choice for the stabilization of intertrochanteric hip fractures [25]. Taheriazam et al, [26] reported that higher the sample size and a sufficient rate of follow-up in this intertrochanteric hip fracture individuals with a lower rate of complications with one approach for total hip arthroplasty (THA). Most subjects that entered in this midterm follow-up had good pain easing and significant functional improvement. Although there are several technical difficulties, there were a few major complications. It could be
Concluded that THA after failed DHS internal fixation of intertrochanteric hip fracture is the best choice. Rathod et al. reported that early operative intervention with DHS with 1350 side plates with barrel gives good results, helps early mobilization of elderly patients decreasing morbidity and mortality, and achieves rigid fixation even in osteoporotic bone. So, DHS still is the implant of choice by many surgeons and has stood against the test of time [8]. This study has certain limitations. The small sample size was low and unable to take pain into account in the clinical outcome analysis as it was felt that there was poor documentation of this data in records.

\section{Conclusion}

Trochanteric fractures are essentially fractured of the elderly, with osteoporotic bones.

\section{What does the study add to the existing knowledge?}

The dynamic hip screw is the operative treatment of choice for stable trochanteric fractures.

\section{Author's Contribution}

Dr. D Rama Rao: Concept, study design

Dr. PV Ramana Chowdary: Manuscript
preparation

Dr. K Aditya: Statistical analysis

Dr. Kiran Deedi: Manuscript preparation

\section{Reference}

01. Falch JA, Liebekk A, Slungaard U. Epideomology of hip fractures in Norway. Acta Orthop Scand. $1986 ; 56(1) 12-16$.

doi:

[Article:https://doi.org/10.3109/1745367850899297

0][Crossref]

02. Wong PCN. Femoral neck fractures among the major racial groups in Singapore, Incidence pattern compared with non-Asian communities. Singapore Med. 1984; J5;150-157.

[Crossref]

03. Boyd HB, Griffin LL. Classification and treatment of intertrochanteric fractures. Arch Surg. $1949 ; 58(6) 853$.

doi:

[Article:https://doi.org/10.1001/archsurg.1949.0124 0030864012][Crossref] 
04. Singh $M$, Nagrath AR, Maini PS. The changes in the trabecular pattern of the upper end of the femur as an index of osteoporosis. J Bone Joint Surg. 1970;52(3)457-467.

[Crossref]

05. Kyle RF, Gustilo RB, Premer RF. Analysis of six hundred and twenty two intertrochanteric hip fractures- A retrospective and prospective study. J Bone Joint Surg. 1979;61(2)216-221. [Crossref]

06. Moore GH, MacEachern AG, Evans J. Treatment of inter-trochanteric fractures of the femur, a comparison of the Richards screw-plate with the Jewett nail-plate. J Bone Joint Surg. 1983;65(3)262-267.

[Crossref]

07. Jonnes C, Shishir SM, Syed Najimudeen S. Type II Intertrochanteric Fractures- Proximal Femoral Nailing (PFN) Versus Dynamic Hip Screw (DHS). Arch Bone Jt Surg. 2016;4(1)23-28.

[Crossref]

08. Rathod J, Tijoriwala P. A study of results of fixation of pertrochanteric femur fractures with dynamic hip screw (DHS) and comparision with past studies. Int J Orthop Sci. 2019;5(3)141147.

doi:[Article:https://doi.org/10.22271/ortho.2019.v5. i3c.1520][Crossref]

09. Ghoneem HF, Zayda AI, Ali El Sayed AF. Treatment of intertrochanteric fracture femur by Ilizarov fixator in elderly patients. Menoufia Med J. 2018;31(4)1293-1298.

Available from:[Article:http://www.mmj.eg.net/text. asp?2018/31/4/1293/252072][Crossref]

10. Parker MJ. Cutting of Dynamic hip screw related to its position. J Bone Joint Surg. 1992; 74(4)625.

[Crossref]

11. Gurlter RA, Jacob RR, Jacob CR. Biomechanical evaluation of enders pins, The Harres nail and the dynamic hip screw for unstable intertrochanteric fractures. Clin Orthop. 1986; $206 ; 109$.

[Crossref]

12. Taheriazam A, Saeidinia A. Salvage of failed dynamic hip screw fixation of intertrochanteric fractures. Orthop Res Rev. 2019;11;93-98.

doi: [Article:https://doi.org/10.2147/ORR.S215240] [Crossref]
13. Esser MP, Kassab JY, Jones DHA. Trochanteric fracture of the femur. J Bone Joint Surg. $1986 ; 68-B ; 557-560$.

[Crossref]

14. Ecker ML, Joyce JJ, Kohl EJ. The treatment of trochanteric hip fractures using compression screw. J Bone Joint Surg. 1975;57(1)23-27. [Crossref]

15. Tan ST, Tan WP, Jaipaul J, Chan SP, Sathappan SS. Clinical outcomes and hospital length of stay in 2,756 elderly patients with hip fractures- a comparison of surgical and non-surgical management. Singapore Med J. 2017;58(5)253257.

doi:[Article:https://doi.org/10.11622/smedj.2016 045][Crossref]

16. Shetty AV, Siyaj AS, Kaushik SB. A comparative study of the results of unstable intertrochanteric fracture treated with cemented bipolar hemiarthroplasty with and without reconstruction of the greater trochanter. Int J Orthop Sci. 2019;5(1)268-271.

doi:[Article:https://doi.org/10.22271/ortho.2019.v5. i1e.46][Crossref]

17. Murugesan AK, Govindasamy R, Ismail PY. Functional outcome of intertrochanteric fractures in elderly patients with proximal femoral nail- Retrospective study. Int $\mathrm{J}$ Res Orthop. 2019;5(4)619-623.

doi: [Article:http://dx.doi.org/10.18203/issn.2455451][Crossref]

18. Yoo J, Lee JS, Kim S, Kim BS, Choi H, Song DY, et al. Length of hospital stay after hip fracture surgery and 1-year mortality. Osteoporos Int. 2019;30(1)145-153.

[Crossref]

19. Tanner DA, Kloseck M, Crilly RG, Chesworth B, Gilliland J. Hip fracture types in men and women change differently with age. Geriatr. 2010;10.

12. doi: [Article:https://doi.org/10.1186/1471-231810-12][Crossref]

20. Ravi. Study on the Efficiency of Fractures Treated With Proximal Femoral Locking Compression Plates. Int J Intg Med Sci. 2015;2(10)191-195.

doi:[Article:http://dx.doi.org/10.16965/ijims.2015. 131][Crossref]

21. Waddell JP, Czitrom A, Simmons EH. Enders nailing in fractures of proximal femur. J Trauma Injury Infect Critical Care. 1987;27;911-916.

[Crossref] 
22. Theja J SS, Marathe K, Gurumurthy B, Kumar PP. Management of intertrochantric fractures with dynamic hip screw and trochanteric femoral nail - A prospective comparative study. MedPulse Int J Orthop. 2019;9(3):65-71.

[Crossref]

23. Parker MJ. Trochanteric hip fractures, fixation failure commoner with femoral medialization, acomparison of 101 cases. Acta Orthop Scand. $1996 ; 67(4) 329-332$.

doi:

[Article:https://doi.org/10.3109/174536796090023

25][Crossref]

24. Kulkarni G S, Limaye R, Kulkarni M, Kulkarni S. Intertrochanteric fractures. Indian $\mathrm{J}$ Orthop. $2006 ; 40 ; 16-23$.

[Crossref]
25. Lee YS, Huang HL, Lo TY, Huang CR. Dynamic hip screw in the treatment of intertrochanteric fractures- a comparison of two fixation methods. Int Orthop. 2007;31(5)683-688.

doi: [Article:https://doi.org/10.1007/s00264-0060248-y][Crossref]

26. Cankaya D, Yoldaş B, Cankaya E, Cakir Y, Aydin C, Tabak AY. Analysis of the hip fracture records of a central training and research hospital by selected characteristics. Turk J Med Sci. $2016 ; 46 ; 35-41$.

doi: [Article:https://doi.org/10.3906/sag-1406-150] [Crossref] 